\title{
CTG-Repeat Detection in Primary Human Myoblasts of Myotonic Dystrophy Type 1
}

\author{
Stefan Hintze ${ }^{\dagger}$, Raphaela Menselt, Lisa Knaier, Benedikt Schoser and Peter Meinke* \\ Department of Neurology, LMU Klinikum, Friedrich-Baur-Institute, Ludwig-Maximilians-University Munich, Munich, Germany
}

Myotonic dystrophy type 1 (DM1) is an autosomal dominant multisystemic disorder caused by unstable CTG-repeat expansions in the DMPK gene. Tissue mosaicism has been described for the length of these repeat expansions. The most obvious affected tissue is skeletal muscle, making it the first target for therapy development. To date there is no approved therapy despite some existing approaches. Thus, there is the demand to further advance therapeutic developments, which will in return require several wellcharacterized preclinical tools and model systems. Here we describe a modified method

OPEN ACCESS

Edited by:

Stojan Z. Peric,

University of Belgrade, Serbia

Reviewed by:

Giovanni Meola,

University of Milan, Italy

Ralf Krahe,

University of Texas MD Anderson

Cancer Center, United States

${ }^{*}$ Correspondence:

Peter Meinke

Peter.Meinke@med.uni-muenchen.de

tThese authors have contributed equally to this work and share first

authorship

Specialty section:

This article was submitted to

Neurogenomics,

a section of the journal

Frontiers in Neuroscience

Received: 27 March 2021

Accepted: 07 June 2021

Published: 28 June 2021

Citation:

Hintze S, Mensel R, Knaier L,

Schoser B and Meinke P (2021)

CTG-Repeat Detection in Primary

Human Myoblasts of Myotonic

Dystrophy Type 1.

Front. Neurosci. 15:686735.

doi: 10.3389/fnins.2021.686735 to identify the CTG-repeat length in primary human myoblasts isolated from DM1 patients that requires less genomic DNA and avoids radioactive labeling. Using this method, we show that primary human DM1 myoblast cultures represent a population of cells with different CTG-repeat length. Comparing DNA from the identical muscle biopsy specimen, the range of CTG-repeat length in the myoblast culture is within the same range of the muscle biopsy specimen. In conclusion, primary human DM1 myoblast cultures are a well-suited model to investigate certain aspects of the DM1 pathology. They are a useful platform to perform first-line investigations of preclinical therapies.

Keywords: myotonic dystrophy type 1, primary human myoblast cultures, CTG-repeats, DMPK, repeat detection

\section{INTRODUCTION}

Myotonic dystrophy type 1 (DM1) is caused by CTG-repeat expansions in the $3^{\prime}$ UTR of the DMPK gene, which are inherited autosomal dominant. Clinically, DM1 is a slowly progressing multisystemic disorder characterized by myotonia, muscle weakness, cataracts, cardiac arrhythmia, and cardiomyopathy, insulin insensitivity and diabetes, testicular atrophy, hypogammaglobulinemia, and involvement of the central nervous system (Udd and Krahe, 2012; Meola and Cardani, 2015; Wenninger et al., 2018). Due to the predominant muscle involvement and the approximate prevalence of 1:8,000 (Faustino and Cooper, 2003; Wheeler, 2008), DM1 is considered to be the most frequent muscular dystrophy in adulthood. There is broad variability of the clinical manifestation of the disease, which ranges from congenital to late adult onset (Echenne and Bassez, 2013; De Antonio et al., 2016; Ho et al., 2019). This can be partly explained by the length of the inherited repeat length, which shows a strong correlation with the age of onset (Cumming et al., 2019; Overend et al., 2019), although there are other contributing factors (Brunner et al., 1993).

Up to 35 CTG triplets in blood derived DNA are normal, a repeat length between 35 and 49 is considered to be a premutation (Udd and Krahe, 2012). Between 50 and $\sim 150$ repeats have been observed in a mild expression of the phenotype and $\sim 100$ to $\sim 1,000$ CTG repeats were identified in patients with classical DM1. Repeats consisting of more than 1,000 CTG-triplets result 
in congenital DM, the most severe expression of the disease (Redman et al., 1993). There is a somatic instability of the repeat expansion which depends on age and repeat size (Wong et al., 1995b) and results in mosaicism (Monckton et al., 1995a). In skeletal muscle the repeat size has been shown to be between 3- and 25-fold higher as in leukocytes (Thornton et al., 1994; Nakamori et al., 2013).

Clinical testing for DM1 is challenging due to the nature of the mutation. The standard method to detect DM1 repeat expansions is still Southern blot of genomic DNA, which is usually performed on DNA isolated from leukocytes (Brook et al., 1992; Kamsteeg et al., 2012). The disadvantages of this method are that it requires large amounts of DNA and that the detection is done by radioactive labeling, which warrants special safety measures. Other methods used are PCR and fragment size analysis by capillary electrophoresis, or triplet-primed PCR followed by fragment size analysis or melt curve analysis (Warner et al., 1996; Kamsteeg et al., 2012; Singh et al., 2014; Turner and Hilton-Jones, 2014; Leferink et al., 2019).

To date there is no therapy available for DM1. The most advanced approach, an antisense-oligonucleotide treatment used for post-transcriptional silencing of $D M P K$, failed in a first clinical trial to reach the sufficient concentration in muscle due to inadequate biodistribution (LoRusso et al., 2018). Thus, there is a demand for further work on development of therapies. This requires the accessibility of suited preclinical tools and model systems, which must be well-characterized. Available DM1 models include animal models like fruit flies, zebrafish, and mice (Sicot and Gomes-Pereira, 2013; Plantié et al., 2015; Souidi et al., 2018), immortalized human cells (Pantic et al., 2016; Arandel et al., 2017), and primary human cell cultures (Savkur et al., 2001; Renna et al., 2017; Hintze et al., 2018).

Considering the predominant muscle involvement in DM1, the usage of primary human myoblasts has several potential advantages. As they can be obtained from several patients, a number of those cultures can be considered to stratify phenotypic variability observed in DM1 patients. Furthermore, they differentiate into myotubes, thus shifting the gene expression profile toward the mature muscle, and proliferating cells allow to investigate cell cycle effects. The latter is also a disadvantage, primary cells enter into replicative senescence after a define number of divisions which is inversely correlated with the age of the donor (Hayflick, 1965). For muscle cells there are roughly 15-20 divisions possible starting from a single satellite cell (Renault et al., 2000), but this turnover number is reduced in DM1 due to premature senescence (Bigot et al., 2009). While this reflects on premature aging aspects of DM1 (Meinke et al., 2018) it also restricts the amount of available material.

Here we describe the characterization of the extended CTGrepeat in primary human myoblasts cultures gained from adult onset DM1 patients, using an adaption of a small-pool PCR/Southern blot protocol (Gomes-Pereira et al., 2004) to non-radioactive labeling. This allows to test the DM1 repeat length using less material without special safety precautions and hopefully extends the accessibility of well-characterized preclinical model systems for testing new therapeutic avenues.

\section{METHODS}

\section{Tissue Culture}

Primary human myoblasts (Table 1) were obtained from the Muscle Tissue Culture Collection (MTCC) at the Friedrich-BaurInstitute (Department of Neurology, LMU Klinikum, LudwigMaximilians-University, Munich, Germany). All materials were obtained with written informed consent of the donor. Ethical approval for this study was obtained from the ethical review committee at the Ludwig-Maximilians-University, Munich, Germany (reference 45-14).

Primary human myoblast from DM1 patients were obtained from patients with adult onset (Table 1). Primary human control myoblasts were obtained from individuals who underwent standard diagnostics due to some muscular issues, but in which neuromuscular disorders have been excluded.

Myoblasts were grown at $37^{\circ} \mathrm{C}$ with $5 \% \mathrm{CO}_{2}$ in $10 \mathrm{~cm}$ tissue culture plates. For cell growth skeletal muscle cell growth medium (PeloBiotech, Munich, Germany), supplemented with $40 \mathrm{U} / \mathrm{ml}$ Penicillin and $0.04 \mathrm{mg} / \mathrm{ml}$ Streptomycin was used, cells were kept from reaching confluency by splitting at a density of about $80 \%$. Myoblasts were harvested between passages 6 and 8 .

\section{DNA Isolation}

To obtain DNA from the primary myoblast cultures cells were trypsinized until they detached from the plate. Cells were pelleted by centrifugation (260 rcf, $5 \mathrm{~min}$ ) and the supernatant was discarded. The cell pellet was washed twice with PBS, each washing step followed by centrifugation $(16,100$ rcf for $1 \mathrm{~min}$ ) and stored at $-80^{\circ} \mathrm{C}$ till further processing. For DNA isolation the Quick-DNA ${ }^{\mathrm{TM}}$ Miniprep Plus Kit (ZymoResearch) was used according to the manufacturer's instructions. DNA concentration was measured by a Nanodrop (Thermo Fisher Scientific).

\section{Size-Marker}

To generate a marker that allowed us to measure the number of CTG-repeats we first amplified a 171 bp DNA fragment, containing 20 CTG repeats, using the DM-C and DM-DR primer published by Monckton et al. (1995a). This amplicon was then blunt-end cloned into a pUC19 plasmid. We named the resulting plasmid pRM1. By restriction digest (EcoRI/HindIII) and ligation of the cut-out fragment (containing the CTG repeats) into a p426MET25HA backbone we created the plasmid pSH1. Both plasmids were amplified in E. coli, purified, and digested using different endonucleases. These specific digestions gave rise to different DNA fragments of defined size containing the 20 CTG repeats (Figure 1).

\section{Dig Probe}

Dig-probes were designed to directly target the repeat and ordered from Eurofins. The probes were labeled $5^{\prime}$ and $3^{\prime}$ with digoxigenin (DIG). Following sequences were used for the sense and antisense strand probes: 
TABLE 1 | Primary myoblast cultures used in this study.

\begin{tabular}{|c|c|c|c|c|c|c|c|}
\hline & \multirow[t]{2}{*}{ Phenotype } & \multirow[t]{2}{*}{ Age of onset } & \multirow[t]{2}{*}{ Age at biopsy } & \multirow[t]{2}{*}{ Sex } & \multirow[t]{2}{*}{ Source of the muscle biopsy } & \multicolumn{2}{|c|}{ CTG-repeat length in } \\
\hline & & & & & & Blood & Muscle \\
\hline DM1-1 & DM1 & 3rd decade & 42 & $\sigma^{7}$ & Biceps brachii muscle & $50-70$ & \\
\hline DM1-2 & DM1 & 2nd decade & 33 & q & Unknown & $300-500$ & \\
\hline DM1-3 & DM1 & 2nd decade & 34 & $\sigma^{7}$ & Deltoid muscle & $240-430$ & $\sim 600$ \\
\hline Con-1 & Unaffected & & 43 & $0^{x}$ & Biceps brachii muscle & - & \\
\hline Con-2 & Unaffected & & 36 & ㅇ & Tibialis anterior muscle & - & \\
\hline
\end{tabular}

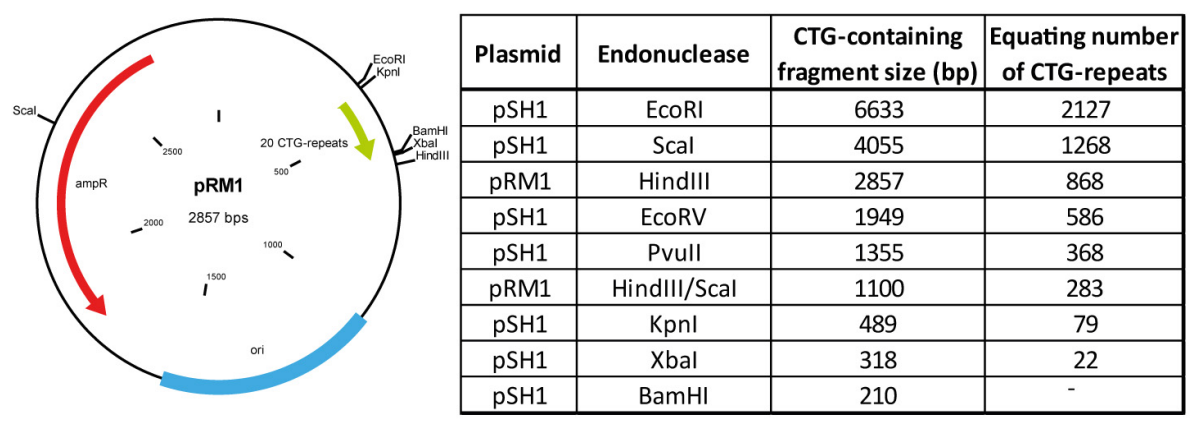

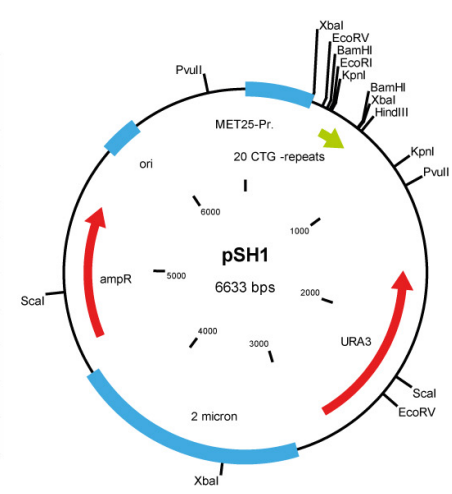

FIGURE 1 | Plasmids used to create the size marker by restriction digest with endonucleases and the resulting sizes of the CTG-repeat containing fragments.

\section{5'-[DIG]-GAATGCTGCTGCTGCTGCTGCTGCTGCTG CTG-[DIG]-3' \\ $5^{\prime}$-[DIG]-CAGCAGCAGCAGCAGCAGCAGCAGCAGC ATTC-[DIG]-3'.}

\section{Small-Pool PCR}

Amplification of the repeat containing DNA was modified after the original protocol by Monckton et al. (1995a). Prior to the polymerase chain reaction (PCR) DNA was diluted to a final amount of $50-300 \mathrm{pg}$ per reaction. It is important to note that we did use a polymerase without proofreading activity for the small pool PCR, as the usage of proof-reading polymerases resulted in insufficient amplification of the repeat containing alleles. PCR reactions were performed in a total volume of $50 \mu \mathrm{l}$ per reaction. The reaction mix contained $1.25 \mathrm{U}$ AmpliTaq ${ }^{\circledR}$ polymerase (AppliedBiosystems), appropriately diluted reaction buffer, $10 \mathrm{mM}$ dNTPs, $100 \mu \mathrm{M}$ of each primer (DM-A and DMBR; Monckton et al., 1995a), and $\mathrm{ddH}_{2} \mathrm{O}$. Primer sequences used are following:

Forward primer: 5'-CAGTTCACAACCGCTCCGAGC-3' Reverse primer: 5'-CGTGGAGGATGGAACACGGAC-3'

Following settings were used for the PCR:

Initial denaturation : $95^{\circ} \mathrm{C} 240 \mathrm{~s}$

$\left(\begin{array}{ll}\text { Denaturation : } & 95^{\circ} \mathrm{C} 45 \mathrm{~s} \\ \text { Annealing : } & 68^{\circ} \mathrm{C} 45 \mathrm{~s} \\ \text { Extension : } & 72^{\circ} \mathrm{C} 180 \mathrm{~s}^{*}\end{array}\right) 28$ cycles

Final extension : $72^{\circ} \mathrm{C} 600 \mathrm{~s}$
*Time increment of $15 \mathrm{~s}$ per cycle.

The PCR was performed in a Biometra Tadvanced thermocycler (Analytik Jena).

\section{Gel Electrophoresis}

The PCR products were size-separated by gel electrophoresis. For this a $1 \%$ agarose gel of $14 \mathrm{~cm}$ length was prepared using Tris-acetate-EDTA (TAE) buffer. The gel was loaded with $30 \mu \mathrm{l}$ of PCR product mixed with $10 \mu \mathrm{l}$ of loading buffer. Initial the electrophoresis was run for $10 \mathrm{~min}$ at $100 \mathrm{~V}$ (volt), followed by $60 \mathrm{~min}$ at $140 \mathrm{~V}$.

\section{Southern Blot}

After the electrophoresis the DNA was transferred via vacuum blot to a nylon membrane (Amersham Hybond ${ }^{\mathrm{TM}}-\mathrm{XL}$ ). The gel was washed in $\mathrm{ddH}_{2} \mathrm{O}$ and placed in depurination buffer for $15 \mathrm{~min}$. After the depurination and a washing step with dd $2 \mathrm{O}$ the gel was placed for $30 \mathrm{~min}$ in denaturation buffer. Before the gel was equilibrated in $20 \times$ SSC buffer for $10 \mathrm{~min}$ it was incubated two times in neutralizing buffer for $15 \mathrm{~min}$. The equilibrated membrane (in $20 \times$ SSC) was placed on the blotting apparatus (vacuum blot, Analytik Jena) and on top the gel. Stepwise the low vacuum of 90-100 mBar was established. During the blotting phase of 1-1.5 h $20 \times$ SSC buffer was constantly added to the top of the gel. Following this, the membrane was equilibrated for $2 \mathrm{~min}$ in $2 \times \mathrm{SSC}$ buffer and then dried for $5 \mathrm{~min}$ at $65^{\circ} \mathrm{C}$ (UVP Hybrilinker Oven, Analytik Jena). Following the drying process, the DNA was cross-linked via UV-light (UVP Hybrilinker Oven, Analytik Jena). Solutions were prepared the following: 


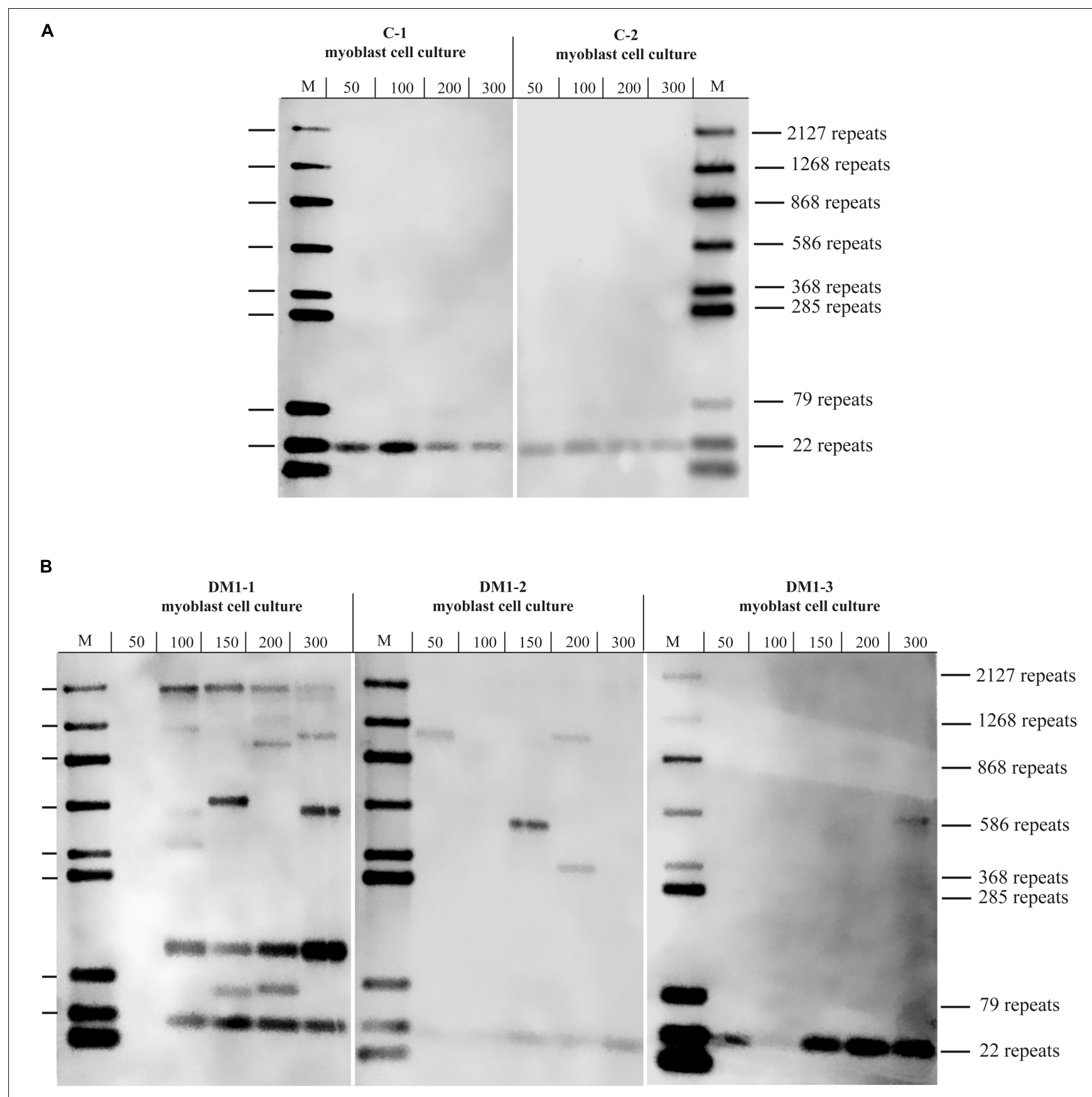

FIGURE 2 | Southern blot for (A) control and (B) DM1 primary myoblast cultures showing the different with the amount of used DNA in pg (as input for the small pool $\mathrm{PCR}$ ) shown. $\mathrm{M}$ = size-marker.

- Depurination buffer $\mathrm{HCl} 0.25 \mathrm{M}$

- Denaturation buffer $\mathrm{NaCl} 1.5 \mathrm{M} ; \mathrm{NaOH} 0.5 \mathrm{M}$

- SSC buffer $(20 \times)$ NaCl 3 M; Ma-Citrate 0.3 M (pH 7.5)

- Neutralizing buffer $\mathrm{NaCl} 1.5 \mathrm{M}$; Tris/HCl $0.5 \mathrm{M}$; EDTA $1 \mathrm{mM}$ (pH 7.2).

\section{Hybridization and Detection}

The membrane was transferred into a prewarmed hybridization tube with $10 \mathrm{ml}$ PerfectHyb ${ }^{\mathrm{TM}}$ Plus hybridization buffer (Sigma
Aldrich) and equilibrated for 15-30 min. In the meantime, $20 \mu \mathrm{l}$ of the two probes $(9 \mathrm{ng} / \mu \mathrm{l})$ where incubated with $80 \mu \mathrm{lddH} \mathrm{d}_{2} \mathrm{O}$ for $10 \mathrm{~min}$ at $100^{\circ} \mathrm{C}$. After the denaturation step the probes where immediately placed on ice for $5 \mathrm{~min}$ and then transferred into the hybridization solution. After the overnight incubation the membrane was washed for $20 \mathrm{~min}$ at $65^{\circ} \mathrm{C}$ with prewarmed $\left(65^{\circ} \mathrm{C}\right)$ washing solution $(1 \times \mathrm{SSC}+0.2 \% \mathrm{SDS})$. After the second washing step the membrane was equilibrated for $5 \mathrm{~min}$ in wash-buffer $(100 \mathrm{mM}$ 
maleic acid $+150 \mathrm{mM} \mathrm{NaCl}+0.3 \%$ Tween20 pH 7.5). Blocking solution (Roche DIG-detection Kit) was set up in maleic buffer (100 mM maleic acid $+150 \mathrm{mM} \mathrm{NaCl} \mathrm{pH}$ 7.5) and then put on the membrane for $30 \mathrm{~min}$. The DIGantibody conjugate (Roche DIG-detection Kit) was diluted in blocking solution and the membrane was incubated for another $30 \mathrm{~min}$. Following two $15 \mathrm{~min}$ washing steps the membrane was equilibrated in detection buffer (Roche DIG-detection Kit) for $5 \mathrm{~min}$. The membrane was incubated for $15 \mathrm{~min}$ at $37^{\circ} \mathrm{C}$ in the detection solution (Roche DIG-detection Kit) before the signals were detected for $10 \mathrm{~min}$ using an Odyssey ${ }^{\circledR} \mathrm{Fc}$ imaging system (Licor).

\section{Calculation of the Repeat Length}

To calculate the actual repeat length the image studio ${ }^{\mathrm{TM}}$ software (Licor) was used to measure the size of the bands detected in samples based on the size of the marker bands. Based on these data the following formula was used:

$$
\mathbf{x}=\frac{\mathbf{y}-\mathbf{z}}{3}+\mathbf{i}
$$

$\mathrm{x}=$ number of repeats.

$\mathrm{y}=$ fragment length (measured using the image studio $^{\mathrm{TM}}$ software, Licor).

$\mathrm{Z}=$ flanking gene sequence $(311 \mathrm{bp})$.

$\mathrm{i}=$ number of the repeats within the marker sequence $(20$ repeats).

\section{RESULTS}

Using two control myoblast cultures we could detect small repeats with the calculated sizes of about 20 CTG-repeats for both (Figure 2A). Those repeats are within the range expected for normal alleles (up to 35 CTG-repeats). In the three DM1 myoblast cultures tested (Figure 2B), we could detect small CTG-repeats (about 20 CTG-repeats) in all of them. This band corresponds to the size of the wildtype allele. For the culture DM1-1 (left) we found several bands ranging from $\sim 50$ to $>2,000$ CTG-repeats. The presence of this range of repeat length could indicate a mosaic situation in the muscle of this patient. In the culture DM1-2 (middle) we could also identify extended CTG-repeats in addition to the wildtype allele. Here the range is between 300 and 1,000 CTG-repeats. In DM1-3 (right) we only got one band for an extended allele of about 600 CTGrepeats.

To test if the repeat length in primary myoblast cultures is comparable to the muscle biopsy they were grown from, we tested material from the cryo-preserved biopsy of DM13 which was part of the biopsy the cell line was grown from and compared directly to the myoblast culture (Figure 3). For the myoblasts (right side of the blot) we got again a band showing about 600 repeats. For the muscle biopsy we got a range from $\sim 100$ to $\sim 1,000$ CTG-repeats for the mutant allele. The wildtype allele of about 20 CTG-repeats was detectable in both samples.

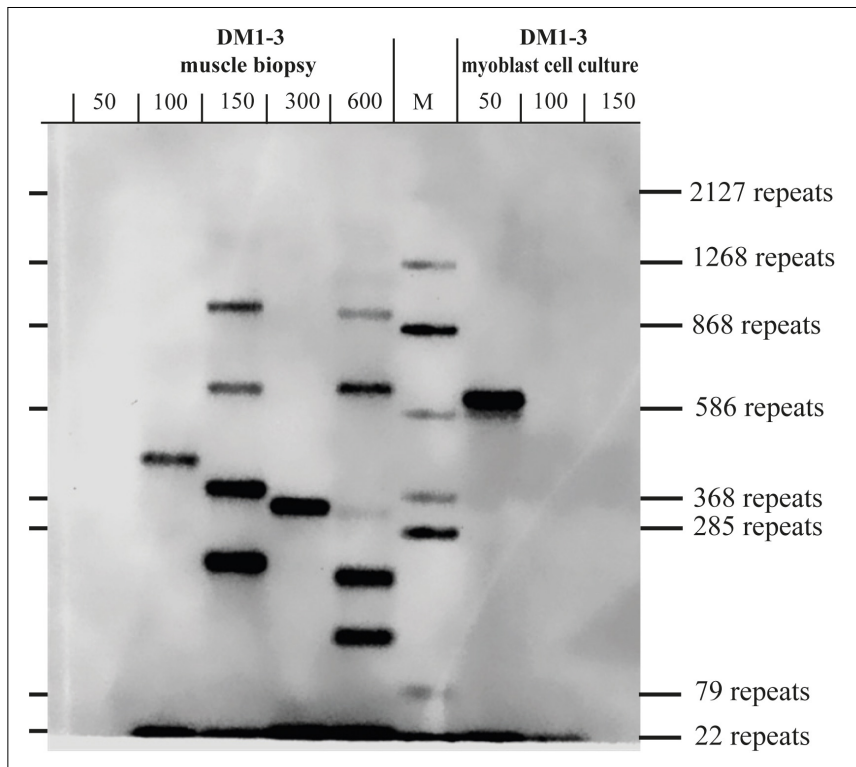

FIGURE 3 | Southern blot comparing DNA derived from a muscle biopsy and a myoblast culture of the same DM1 patient (both samples taken at the same time). For each lane the amount of used DNA in pg (as input for the small pool $\mathrm{PCR}$ ) is shown. $\mathrm{M}=$ size-marker.

\section{CONCLUSION}

With our modified method, we can successfully identify extended CTG-repeats in primary human myoblast cultures in comparison to DNA extracted from the original muscle specimen it was grown from. We show that there is a range of different repeat lengths in myoblast cultures. Thus, human myoblast cultures reflect rather well the repeat-length of mature muscle. Furthermore, it seems that the repeat length in myoblasts and muscle does, for the patient samples tested, not differ significantly from each other. Consequently, we show that primary human DM1 myoblast cultures are a well-suited model to investigate repeat-length related preclinical aspects of the DM1 pathology and are a useful platform to do first-line treatment interventions.

Presently, there are several distinct methods for the detection of CTG-repeats published (Warner et al., 1996; Kamsteeg et al., 2012; Singh et al., 2014; Turner and Hilton-Jones, 2014; Leferink et al., 2019). Most of them require sophisticated and often expensive equipment like capillary sequencers or a laboratory equipped for the usage of radioactive material. The modified method described here is an alternative method to detect CTG-repeat length, which is useful when only limited sample material and no special equipment is available. The usage of PCR-based DNA amplification is a limiting factor as the length of DNA, that can be synthesized by polymerases, is limited. However, this type of limitation also applies for any other method using polymerase-depending amplification. 


\section{DATA AVAILABILITY STATEMENT}

The original contributions presented in the study are included in the article/supplementary material, further inquiries can be directed to the corresponding author/s.

\section{ETHICS STATEMENT}

The studies involving human participants were reviewed and approved by the Ethical Review Committee at the Ludwig-Maximilians-University, Munich, Germany. The patients/participants provided their written informed consent to participate in this study.

\section{REFERENCES}

Arandel, L., Polay Espinoza, M., Matloka, M., Bazinet, A., De Dea Diniz, D., Naouar, N., et al. (2017). Immortalized human myotonic dystrophy muscle cell lines to assess therapeutic compounds. Dis. Model. Mech. 10, 487-497.

Bigot, A., Klein, A. F., Gasnier, E., Jacquemin, V., Ravassard, P., Butler-Browne, G., et al. (2009). Large CTG repeats trigger p16-dependent premature senescence in myotonic dystrophy type 1 muscle precursor cells. Am. J. Pathol. 174, 1435-1442. doi: 10.2353/ajpath.2009.080560

Brook, J. D., McCurrach, M. E., Harley, H. G., Buckler, A. J., Church, D., Aburatani, H., et al. (1992). Molecular basis of myotonic dystrophy: expansion of a trinucleotide (CTG) repeat at the $3^{\prime}$ end of a transcript encoding a protein kinase family member. Cell 68, 799-808. doi: 10.1016/0092-8674(92) 90154-5

Brunner, H. G., Brüggenwirth, H. T., Nillesen, W., Jansen, G., Hamel, B. C., Hoppe, R. L., et al. (1993). Influence of sex of the transmitting parent as well as of parental allele size on the CTG expansion in myotonic dystrophy (DM). Am. J. Hum. Genet. 53, 1016-1023.

Cumming, S. A., Jimenez-Moreno, C., Okkersen, K., Wenninger, S., Daidj, F., Hogarth, F., et al. (2019). Genetic determinants of disease severity in the myotonic dystrophy type 1 OPTIMISTIC cohort. Neurology 93, e995-e1009.

De Antonio, M., Dogan, C., Hamroun, D., Mati, M., Zerrouki, S., Eymard, B., et al. (2016). Unravelling the myotonic dystrophy type 1 clinical spectrum: a systematic registry-based study with implications for disease classification. Rev. Neurol. 172, 572-580. doi: 10.1016/j.neurol.2016.08.003

Echenne, B., and Bassez, G. (2013). Congenital and infantile myotonic dystrophy. Handb. Clin. Neurol. 113, 1387-1393. doi: 10.1016/b978-0-444-59565-2. 00009-5

Faustino, N. A., and Cooper, T. A. (2003). Pre-mRNA splicing and human disease. Genes Dev. 17, 419-437. doi: 10.1101/gad.1048803

Gomes-Pereira, M., Bidichandani, S. I., and Monckton, D. G. (2004). Analysis of unstable triplet repeats using small-pool polymerase chain reaction. Methods Mol. Biol. 277, 61-76.

Hayflick, L. (1965). The limited in vitro lifetime of human diploid cell strains. Exp. Cell Res. 37, 614-636. doi: 10.1016/0014-4827(65)90211-9

Hintze, S., Knaier, L., Limmer, S., Schoser, B., and Meinke, P. (2018). Nuclear envelope transmembrane proteins in myotonic dystrophy type 1. Front. Physiol. 9:1532. doi: 10.3389/fphys.2018.01532

Ho, G., Carey, K. A., Cardamone, M., and Farrar, M. A. (2019). Myotonic dystrophy type 1: clinical manifestations in children and adolescents. Arch. Dis. Child. 104, 48-52. doi: 10.1136/archdischild-2018-314837

Kamsteeg, E. J., Kress, W., Catalli, C., Hertz, J. M., Witsch-Baumgartner, M., Buckley, M. F., et al. (2012). Best practice guidelines and recommendations on the molecular diagnosis of myotonic dystrophy types 1 and 2. Eur. J. Hum. Genet. 20, 1203-1208. doi: 10.1038/ejhg.2012.108

Leferink, M., Wong, D. P. W., Cai, S., Yeo, M., Ho, J., Lian, M., et al. (2019). Robust and accurate detection and sizing of repeats within the DMPK gene using a novel TP-PCR test. Sci. Rep. 9:8280.

\section{AUTHOR CONTRIBUTIONS}

$\mathrm{SH}, \mathrm{BS}$, and PM contributed to the conception and design of the experiments. $\mathrm{PM}$ and $\mathrm{SH}$ wrote the manuscript. SH, RM, and LK performed the experiments. All authors contributed to the article and approved the submitted version.

\section{FUNDING}

This work was supported by the generosity of Metin Colpan as well as the FöFoLe Grant Reg.-Nr. 959 (LMU) and the FriedrichBaur-Stiftung Grant Reg.-Nr. 65/18 awarded to PM.

LoRusso, S., Weiner, B., and Arnold, W. D. (2018). Myotonic dystrophies: targeting therapies for multisystem disease. Neurotherapeutics $15,872-884$. doi: $10.1007 /$ s13311-018-00679-z

Meinke, P., Hintze, S., Limmer, S., and Schoser, B. (2018). Myotonic dystrophy-a progeroid disease? Front. Neurol. 9:601. doi: 10.3389/fneur.2018.00601

Meola, G., and Cardani, R. (2015). Myotonic dystrophies: an update on clinical aspects, genetic, pathology, and molecular pathomechanisms. Biochim. Biophys. Acta 1852, 594-606. doi: 10.1016/j.bbadis.2014.05.019

Monckton, D. G., Wong, L. J., Ashizawa, T., and Caskey, C. T. (1995a). Somatic mosaicism, germline expansions, germline reversions and intergenerational reductions in myotonic dystrophy males: small pool PCR analyses. Hum. Mol. Genet. 4, 1-8. doi: 10.1093/hmg/4.1.1

Nakamori, M., Sobczak, K., Puwanant, A., Welle, S., Eichinger, K., Pandya, S., et al. (2013). Splicing biomarkers of disease severity in myotonic dystrophy. Ann. Neurol. 74, 862-872. doi: 10.1002/ana.23992

Overend, G., Légaré, C., Mathieu, J., Bouchard, L., Gagnon, C., and Monckton, D. G. (2019). Allele length of the DMPK CTG repeat is a predictor of progressive myotonic dystrophy type 1 phenotypes. Hum. Mol. Genet. 28, 2245-2254. doi: 10.1093/hmg/ddz055

Pantic, B., Borgia, D., Giunco, S., Malena, A., Kiyono, T., Salvatori, S., et al. (2016). Reliable and versatile immortal muscle cell models from healthy and myotonic dystrophy type 1 primary human myoblasts. Exp. Cell Res. 342, 39-51. doi: 10.1016/j.yexcr.2016.02.013

Plantié, E., Migocka-Patrzałek, M., Daczewska, M., and Jagla, K. (2015). Model organisms in the fight against muscular dystrophy: lessons from drosophila and Zebrafish. Molecules 20, 6237-6253. doi: 10.3390/molecules200 46237

Redman, J. B., Fenwick, R. G. Jr., Fu, Y. H., Pizzuti, A., and Caskey, C. T. (1993). Relationship between parental trinucleotide GCT repeat length and severity of myotonic dystrophy in offspring. Jama 269, 1960-1965. doi: 10.1001/jama. 1993.03500150072029

Renault, V., Piron-Hamelin, G., Forestier, C., DiDonna, S., Decary, S., Hentati, F., et al. (2000). Skeletal muscle regeneration and the mitotic clock. Exp. Gerontol. 35, 711-719. doi: 10.1016/s0531-5565(00)00151-0

Renna, L. V., Bosè, F., Iachettini, S., Fossati, B., Saraceno, L., Milani, V., et al. (2017) Receptor and post-receptor abnormalities contribute to insulin resistance in myotonic dystrophy type 1 and type 2 skeletal muscle. PLoS One 12:e0184987. doi: 10.1371/journal.pone.0184987

Savkur, R. S., Philips, A. V., and Cooper, T. A. (2001). Aberrant regulation of insulin receptor alternative splicing is associated with insulin resistance in myotonic dystrophy. Nat. Genet. 29, 40-47. doi: 10.1038/ng704

Sicot, G., and Gomes-Pereira, M. (2013). RNA toxicity in human disease and animal models: from the uncovering of a new mechanism to the development of promising therapies. Biochim. Biophys. Acta 1832, 1390-1409. doi: 10.1016/ j.bbadis.2013.03.002

Singh, S., Zhang, A., Dlouhy, S., and Bai, S. (2014). Detection of large expansions in myotonic dystrophy type 1 using triplet primed PCR. Front. Genet. 5:94. doi: 10.3389/fgene.2014.00094 
Souidi, A., Zmojdzian, M., and Jagla, K. (2018). Dissecting pathogenetic mechanisms and therapeutic strategies in drosophila models of myotonic dystrophy type 1. Int. J. Mol. Sci. 19:4104. doi: 10.3390/ijms19124104

Thornton, C. A., Johnson, K., and Moxley, R. T. III (1994). Myotonic dystrophy patients have larger CTG expansions in skeletal muscle than in leukocytes. Ann. Neurol. 35, 104-107. doi: 10.1002/ana.410350116

Turner, C., and Hilton-Jones, D. (2014). Myotonic dystrophy: diagnosis, management and new therapies. Curr. Opin. Neurol. 27, 599-606. doi: 10.1097/ wco.0000000000000128

Udd, B., and Krahe, R. (2012). The myotonic dystrophies: molecular, clinical, and therapeutic challenges. Lancet Neurol. 11, 891-905. doi: 10.1016/s14744422(12)70204- 1

Warner, J. P., Barron, L. H., Goudie, D., Kelly, K., Dow, D., Fitzpatrick, D. R., et al. (1996). A general method for the detection of large CAG repeat expansions by fluorescent PCR. J. Med. Genet. 33, 1022-1026. doi: 10.1136/jmg.33.12.1022

Wenninger, S., Montagnese, F., and Schoser, B. (2018). Core clinical phenotypes in myotonic dystrophies. Front. Neurol. 9:303. doi: 10.3389/fneur.2018.00303
Wheeler, T. M. (2008). Myotonic dystrophy: therapeutic strategies for the future. Neurotherapeutics 5, 592-600. doi: 10.1016/j.nurt.2008. 08.001

Wong, L. J., Ashizawa, T., Monckton, D. G., Caskey, C. T., and Richards, C. S. (1995b). Somatic heterogeneity of the CTG repeat in myotonic dystrophy is age and size dependent. Am. J. Hum. Genet. 56, 114-122.

Conflict of Interest: The authors declare that the research was conducted in the absence of any commercial or financial relationships that could be construed as a potential conflict of interest.

Copyright (C) 2021 Hintze, Mensel, Knaier, Schoser and Meinke. This is an open-access article distributed under the terms of the Creative Commons Attribution License (CC BY). The use, distribution or reproduction in other forums is permitted, provided the original author(s) and the copyright owner(s) are credited and that the original publication in this journal is cited, in accordance with accepted academic practice. No use, distribution or reproduction is permitted which does not comply with these terms. 